\title{
Subregional Income Differentials: A Study Of The Tennessee Valley Region \#
}

\author{
Charles B. Garrison and Hui S. Chang*
}

\section{INTRODUCTION}

It is well documented that regional variations in per capita incomes have declined significantly over time in the United States. Browne [1], for example, recently measured the convergence in regional incomes for the nine Census divisions of the U.S. that has occurred since 1940. But income differentials may persist, and be a cause of concern, among smaller geographic areas within a major regional division. Such is our concern in this paper. We investigate the causes of income differentials, the extent of income convergence, and the causes of such convergence among small areas within the Tennessee Valley Region.

The Tennessee Valley Region consists of 210 counties located in Tennessee, southwestern Virginia, western North Carolina, northern Georgia, northern Alabama, northeastern Mississippi, and western Kentucky. For purposes of this study we take as our units of observation the seven "administrative districts" designated by the Tennessee Valley Authority: Alabama, Appalachian, Central, Kentucky, Mississippi, Southeastern, and Western (see Map). As we demonstrate below, the seven districts differ considerably in per capita income levels, but there has been a recent tendency toward convergence.

The seven districts also differ in their economic, cultural, and geographic characteristics. In particular, they differ as to degree of urbanization, in that the presence of large metropolitan centers is less important in some of the districts than in others. The focus of this paper is influenced by the facts that (i) income levels in these urban centers are high, due to past economic development, which is manifested partly in large, inherited concentrations of manufacturing employment, (ii) rural and small-town counties tend to have lower per capita income levels but comprise a sizable fraction of the TVA region's population, and (iii) beginning in the 1960s, manufacturing employment began to grow rapidly in the region's rural and small-town counties. We are thus led toward a model in which income convergence depends on the ability of these latter counties to achieve

*Department of Economics, The University of Tennessee, Knoxville.

\#The authors are grateful to two anonymous referees for a number of useful comments. 


\section{TVA ADMINISTRATIVE DISTRICTS}

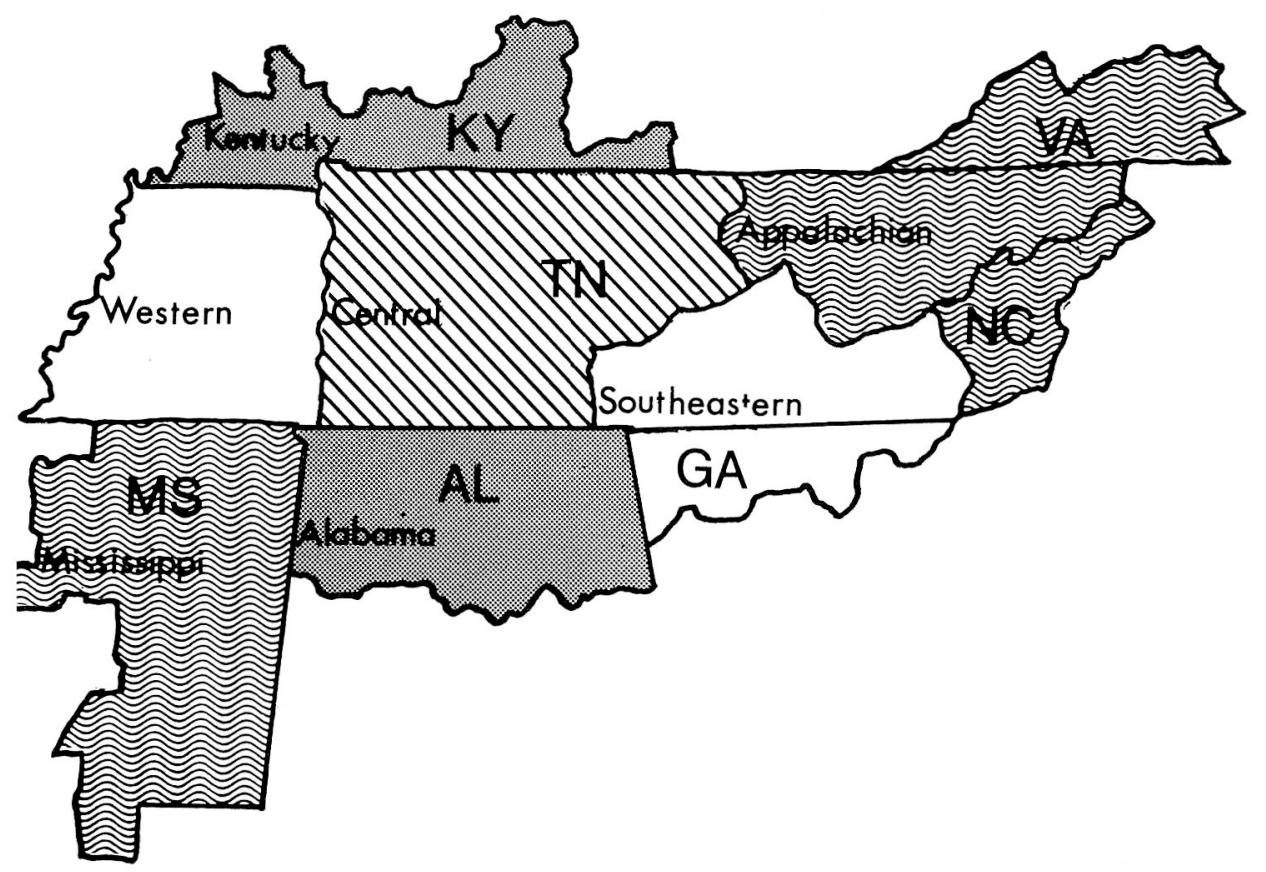

higher income growth rates than the metropolitan counties achieve. In terms of the geographic areas studied here, convergence depends on higher growth rates in those TVA districts which are less urbanized. Further, we will contend that the major source of such higher growth rates is manufacturing activity.

In particular, we test the following hypotheses: First, that a major determinant of differences in per capita income levels as between the seven districts is the level of manufacturing employment. Second, that a major determinant of income convergence, that is, faster income growth in the lower-income, less urbanized districts, is more rapid growth in manufacturing employment in these districts. Finally, we test a third, related hypothesis: that periodic restrictive fiscal and monetary policies designed to combat inflation at the national level have an adverse effect on local-area manufacturing growth and, by implication, on income convergence. We interpret our empirical evidence as providing strong support for each of the three hypotheses.

\section{THE EXTENT OF DIFFERENTIALS IN THE REGION}

We first provide data to document our claim that the seven TVA districts differ as to degree of urbanization (see Table 1). For our purposes, we 
consider a district "urbanized" if it contained as of 1970 a Standard Metropolitan Statistical Area of at least "intermediate" size. ${ }^{1}$ By this criterion, the Appalachian, Central, Southeastern, and Western districts are more urbanized than the Kentucky and Mississippi districts. The Alabama district assumes an in-between position; its largest SMSA, Huntsville, was smaller than the metropolitan areas in the former four districts.

In Table 2 we provide data which establish that (i) a considerable differential exists in per capita income levels as between the seven TVA districts and (ii) there occurred a trend toward convergence of income over the study period, 1968 to 1978 . (Money income has been deflated by the consumer price index, so that income figures are stated in real terms.) The differential as of 1968 was attributable mainly to per capita incomes in the two highest-level districts (the Central and Western districts) being well above those in the two lowest-level districts (the Kentucky and Mississippi districts). Thus per capita income was 43 percent higher in the Central than in the Mississippi district. All seven districts enjoyed sizable increases in per capita income over the period, but the percentage changes were considerably higher in the Kentucky and Mississippi districts than in the Central and Western districts, with the result that fairly strong convergence occurred. In fact, the Mississippi and Kentucky districts had the two highest growth rates in the region, while the Central and Western districts ranked only sixth and fifth, respectively.

It is worth emphasizing that real income increased at impressive rates during the period 1968 to 1978 . This holds true for both the national economy and the economy of the TVA region. Much of the credit for the real income gains is due to large increases in employment. Table 3 documents the employment growth of the period. The underlying reason for the convergence of incomes also begins to emerge: the Mississippi District enjoyed the highest growth rate of employment and the Western District had the second lowest rate. But this line of reasoning carries us only part

TABLE 1

Metropolitan Areas in the Tennessee Valley Region

\begin{tabular}{llc}
\hline \multicolumn{1}{c}{ District } & \multicolumn{1}{c}{ SMSA $^{\mathrm{a}}$} & $\begin{array}{c}\text { SMSA Pop- } \\
\text { ulation, 1970 }\end{array}$ \\
\hline 1. Alabama & Huntsville & 228,239 \\
2. Appalachian & Knoxville & 400,337 \\
3. Central & Nashville & 541,108 \\
4. Kentucky & None & - \\
5. Mississippi & None & - \\
6. Southeastern & Chattanooga & 304,927 \\
7. Western & Memphis & 770,120 \\
\hline
\end{tabular}


TABLE 2

Real Per Capita Personal Income (PIPC), TVA Administrative Districts

\begin{tabular}{lrrc}
\hline \multicolumn{1}{c}{ District } & PIPC & PIPC & $\begin{array}{c}\text { Rank In } \\
\text { Percent Change } \\
\text { of PIPC, 1968-78 }\end{array}$ \\
\hline 1. Alabama & 1968 & 1978 & 3 \\
2. Appalachian & $\$ 2,358$ & $\$ 3,185$ & 4 \\
3. Central & 2,314 & 3,114 & 6 \\
4. Kentucky & 2,629 & 3,418 & 2 \\
5. Mississippi & 2,297 & 3,137 & 1 \\
6. Southeastern & 1,837 & 2,646 & 5 \\
7. Western & 2,456 & 3,183 & \\
PIPC = per capita personal income, in 1967 dollars. & \\
Source: Tennessee Valley Authority data bank. &
\end{tabular}

way in explaining income convergence: the Kentucky district had the second highest growth rate of per capita income but the lowest growth rate of employment. It is our view that manufacturing growth plays a key role in providing a more complete explanation of income growth at the county and multi-county level.

Table 3 provides information regarding growth rates of manufacturing employment. At first glance there appears to be little relationship between income growth rate and growth in manufacturing employment. For example, the Western District grew by only 13.8 percent in manufacturing employment, but by 27.0 percent in total nonagricultural employment and by 33.3 percent in real per capita income. Much the same pattern prevails

TABLE 3

Percent Change In Economic And Demographic Variables, 1968 to 1978, TVA Administrative Districts

\begin{tabular}{lcccc}
\hline \multicolumn{1}{c}{ District } & \multicolumn{4}{c}{ Percent Change } \\
& PIPC & E & EMFG & POP \\
\hline 1. Alabama & 35.0 & 33.1 & 42.4 & 10.2 \\
2. Appalachian & 34.6 & 30.8 & 14.7 & 12.8 \\
3. Central & 30.0 & 34.3 & 23.0 & 15.5 \\
4. Kentucky & 36.6 & 23.7 & 30.4 & 11.6 \\
5. Mississippi & 44.1 & 37.5 & 40.0 & 7.4 \\
6. Southeastern & 29.6 & 30.8 & 11.5 & 14.2 \\
7. Western & 33.3 & 27.0 & 13.8 & 7.6 \\
E = total nonagricultural employment. & & & \\
EMFG = manufacturing employment. & & & \\
POP = population. & & & \\
Source: Tennessee Valley Authority data bank. \\
\hline
\end{tabular}


in the Appalachian, Central, and Southeastern Districts; that is, growth rates in per capita income and total employment were markedly greater than growth rates in manufacturing employment. Based on these relationships, one might conclude that solid income gains can occur with only modest manufacturing growth. But a sharply different pattern emerges in the Alabama, Kentucky, and Mississippi districts: manufacturing employment growth rates exceed total employment growth rates. Further, these three districts had the highest growth rates in manufacturing employment and also the highest growth rates in per capita income.

It is obvious, then, that the relationship between manufacturing growth and income growth at the district level is not a simple one. Further, the nature of the relationship is an important one from the point of view of regional policy. Indeed, one might conclude that it would be a mistake for a region to attempt to raise its income level via a strategy of attracting manufacturing activity, because rapid manufacturing growth does not necessarily bring rapid gains in nonmanufacturing employment. We contend that such a conclusion, however, is not warranted, and that manufacturing growth provides the major potential for improving income growth in the lower income districts of the region. This relationship is of such importance that we devote the next section to a fuller consideration of manufacturing's role.

\section{THE ROLE OF MANUFACTURING}

In a 1974 study of the Tennessee Valley Region, Garrison [2] documented the differential role of manufacturing as a source of economic growth in metropolitan and nonmetropolitan counties. In particular, he found that, during the period 1959 to 1968 , manufacturing employment increased by 175,900 , or 69.2 percent in the nonmetropolitan group, and by 56,400 or only 28.7 percent in the metropolitan counties. Further, the more rural the county, in general the faster was the rate of growth. Thus to a considerable degree the dream of rural, smalltown, and small-city counties to achieve economic growth by "industrializing" was being realized. Manufacturing growth, however, was not the complete answer to achieving a second goal, elimination of population outmigration from such areas (Garrison, [2], p. 56). This is an important factor limiting income growth in nonmetropolitan areas, for population growth itself is a major source of economic growth. This is true because population growth brings with it a demand for new housing, a wider variety of consumer goods and services, and increased investment in new and expanded retail, wholesale, and service establishments. But if increased manufacturing activity employs mainly local labor, and if the existing housing stock and existing trade and service physical capacity is not strained by the additional manufacturing income, these "secondary" sources of economic growth largely will be absent. It will be our contention here that this scenario characterizes, to an important degree, the industrialization process in nonmetropolitan areas, and that this reconciles the simultaneous rapid 
growth of manufacturing on the one hand, and slower growth of nonmanufacturing employment and population, on the other hand, in such areas. But this is in no way detracts from the argument that manufacturing is a major vehicle to income growth; indeed, it suggests that, without manufacturing growth, there would be no important basic source of income improvement in such areas.

Consider the two districts in which metropolitan influences are least important, the Kentucky and Mississippi districts. These two districts had two of the three highest growth rates in manufacturing from 1968 to 1978, but both were below the region-wide average rate of population growth, and in fact Mississippi had the lowest population growth rate (Table 3). The district with the most impressive rate of population growth (the Central) had an intermediate rate of manufacturing employment growth. Are we to conclude that efforts to attract manufacturing activity are not an effective means of raising incomes and at least reducing outmigration? Those who answer in the affirmative point out that those counties (and districts) achieving the greatest population growth have done so mainly by increasing nonmanufacturing employment. Such observers may also point out that, in any event, many manufacturing jobs tend to be low-wage and thus support relatively little population growth. We contend that such an analysis is superficial in that it ignores basic structural differences between smalltown and metropolitan economies.

There is strong evidence that the major explanation of the population change pattern in the TVA region is found in the lower income and employment multipliers in the less urbanized counties (and districts). The community income multiplier varies directly with city size, due to a greater variety of goods and services in larger cities and therefore smaller leakages from the local income stream. But in addition, it appears that in less urbanized counties the employment multiplier effect is smaller than the income effect, due to previously existing underutilization of labor and capital in the local retail and services sectors of such counties. Thus in the Garrison study it was found that the 138 least-urbanized counties in the TVA region accounted for 39.1 percent of manufacturing employment growth in the region from 1959 to 1968 , but for only 21.1 percent of "nonbasic" employment growth.

The above pattern may be a natural outgrowth of the observed fact that much of the new manufacturing industry in rural and small-town counties relies upon local labor. Indeed, a favorable labor supply is a major location advantage of such communities. But because the new firms largely draw their employees from existing residents, and because a given manufacturing payroll will produce fewer new nonbasic jobs than in larger cities, it is not surprising that less-urbanized counties experience only modest population increases. In turn, such a pattern does not produce a burst of residential construction-a major source of "nonbasic" employment growth in larger cities. Of course, if manufacturing development continues over time in less-urbanized counties, the existing capital stock (including housing) becomes inadequate and nonbasic multiplier effects assume greater importance. 
It may be objected that the present study is concerned with areas considerably larger than a single county, and that these considerations are irrelevant. To some extent this is true. Thus, new manufacturing activity in a rural Middle Tennessee county may stimulate trade and services in Nashville: ultimately income, nonmanufacturing employment, and population are increased in the Central District. But it may also be the case that new manufacturing activity in, say, rural western Kentucky stimulates trade and services in Nashville, that is, in a different administrative district. Rural Mississippi might bear the same type of relationship with Memphis. Thus it is a matter of degree; in the Kentucky and Mississippi districts, rural and small-town counties account for a proportionately large part of the economies of the two districts, and despite manufacturing growth rates well above the average for the entire region, their population growth rates are below the average.

Table 3 may be viewed as a summary of the relationships analyzed above. In the four districts which contain the larger metropolitan areas (the Appalachian, Central, Southeastern, and Western), the growth rates for total nonagricultural employment exceed the growth rates for manufacturing employment. This indicates a relatively large multiplier effect for increases in basic activity (including manufacturing) and also a more diversified economic base. Further, in three of these four districts the rate of population growth exceeds the region-wide average. Similar analysis for the three less-urbanized districts suggests smaller employment multipliers and an economic base in which manufacturing is paramount. Further, population growth was below the region-wide average in all three of these districts.

Viewed in the way indicated by this analysis, manufacturing can be a prime source of economic growth, especially for less-urbanized districts and for less-urbanized counties within a given district. Such areas must rely on growth in their own basic activities, principally manufacturing. Further, due to small multipliers and manufacturing-dominated basic activity, multiplier effects on trade, services, and residential construction in such areas will be small. Nevertheless, the observation that the three districts with the highest growth rates in the TVA region in manufacturing employment also had the three highest growth rates in per capita income is consistent with the view that manufacturing is an effective route to economic improvement.

Indeed, the hypothesis may be stated even more strongly: manufacturing is the only promising source of economic growth for the less-urbanized districts and for less-urbanized counties in all the districts. Economic development resulting from providing a wide variety of goods and services to its own residents and to those of surrounding counties is a viable route to growth in metropolitan counties but by definition is less available or not available at all to less-urbanized counties. (It should be noted, however, that as a less-urbanized county or district grows, its trade and services sector can grow and become more diversified, so that nonmanufacturing jobs will become a relatively more important component of growth.) 


\section{STATISTICAL RESULTS}

The Model. In this section we present the results of empirical studies undertaken to test the propositions of the preceding sections. First, however, it is desirable to state these propositions in a more explicit form-that is, in the form of a model. The model employed here may be viewed as a system of three equations:

(1) $Y_{i t}=Y B_{i t}+Y N_{i t}$

(2) $\mathrm{YN}_{\mathrm{it}}=\alpha \mathrm{YB}_{\mathrm{it}}, \alpha>0$

(3) $\mathrm{YB}_{\mathrm{it}}=\beta_{1} \mathrm{M}_{\mathrm{t}}+\beta_{2} \mathrm{DEF}_{\mathrm{t}}+\sum_{\mathrm{j}=1}^{\mathrm{J}} \lambda_{\mathrm{j}} \mathrm{S}_{\mathrm{jit}}, \beta_{1}>0, \beta_{2}>0$,

where

$\mathrm{Y}_{\mathrm{it}}=$ real income in area $\mathrm{i}$ in time $\mathrm{t}$,

$\mathrm{YB}=$ basic income,

$\mathrm{YN}=$ nonbasic income,

$\mathrm{M}=\mathrm{a}$ measure of national monetary policy, such as the rate of money growth,

$\mathrm{DEF}=$ a measure of national fiscal policy, such as the highemployment budget deficit,

$\mathrm{S}_{\mathrm{jit}} \quad=\quad$ a vector of $\mathrm{J}$ supply variables characterizing the ith area in time t.

Equation 1 is an identity stating that an area's real income is the sum of real income from basic sources and from nonbasic sources. Equation 2 is the area's economic base multiplier relationship, where $\alpha$, the multiplier, depends positively on the variety of nonbasic goods and services available. Thus $\alpha$ is a measure of an area's ability to retain export-generated income. Basic income may be derived from a variety of activities, although we are here especially concerned with manufacturing's role in the economic base. The "other" basic activities would include agriculture, mining, tourism, a portion of property income, and transfer payments. Further, if an area provides services (professional, financial, medical, etc.) and retail goods to residents of other areas, YB would include income so earned.

Equation 3 states that an area's export (basic) income is a function of national monetary and fiscal policy and local supply variables. With regard to the national policy variables, the expectation is that basic employment 
TABLE 4

Regression Of Personal Income Per Capita

On Explanatory Variables, 1968-78, TVA Regiona

\begin{tabular}{|c|c|c|c|c|c|c|c|c|}
\hline \multirow{2}{*}{$\begin{array}{l}\text { Equation } \\
\text { Number }\end{array}$} & \multirow{2}{*}{$\begin{array}{c}\text { Dependent } \\
\text { Variable }\end{array}$} & \multicolumn{6}{|c|}{ Independent Variables } & \multirow[b]{2}{*}{$\mathrm{R}^{2}$} \\
\hline & & Constant & EMFG & SFLOW & LNDAG & SCHYR & TIME & \\
\hline 4.1 & PIPC & $\begin{array}{l}-2.96 * * \\
(-4.93)\end{array}$ & $\begin{array}{l}2.17 * * \\
(4.04)\end{array}$ & & & & $\begin{array}{l}74.71 * * \\
(9.04)\end{array}$ & 59 \\
\hline 4.2 & PIPG & $\begin{array}{l}1.72 * * \\
(8.32)\end{array}$ & $\begin{array}{l}2.08 * * \\
(2.36)\end{array}$ & $\begin{array}{l}1.30 * * \\
(5.12)\end{array}$ & $\begin{array}{l}0.72 * * \\
(2.60)\end{array}$ & & & .42 \\
\hline 4.3 & PIPC & $\begin{array}{l}-4.96^{* * *} \\
(-5.35)\end{array}$ & $\begin{array}{l}2.24 * * \\
(4.35)\end{array}$ & & & $\begin{array}{l}.019 * * \\
(2.75)\end{array}$ & $\begin{array}{l}74.57 * * \\
(9.41)\end{array}$ & .63 \\
\hline 4.4 & PIPC & $\begin{array}{l}-3.23 * * \\
(-5.53)\end{array}$ & $\begin{array}{l}3.17 * * \\
(4.99)\end{array}$ & & $\begin{array}{l}0.59 * * \\
(2.70)\end{array}$ & & $\begin{array}{l}72.8^{* *} \\
(9.14)\end{array}$ & .63 \\
\hline 4.5 & PIPC & $\begin{array}{l}-5.83^{* *} \\
(-6.55)\end{array}$ & $\begin{array}{l}3.54 * * \\
(5.94)\end{array}$ & & $\begin{array}{l}0.76^{* * *} \\
(3.64)\end{array}$ & $\begin{array}{l}24.3 * * \\
(3.67)\end{array}$ & $\begin{array}{l}72.1 * * \\
(9.80)\end{array}$ & .69 \\
\hline
\end{tabular}

${ }^{a}$ The $t$-values appear below each coefficient and are enclosed by parentheses. The regression coefficients marked by ** are statistically significant at the 5 percent level, PIPC is in dollars, EMFG is in thousands of employees, SFLOW is in number of river-miles of streamflow in excess of 400 c.f.s., LNDAG is the percentage of land devoted to agriculture, and SCHYR is educational level as measured by median school years completed by the population over 25 in 1970 . Time is in calendar years. 
and income will increase if the rate of growth of the money supply increases or if the federal budget deficit ${ }^{2}$ increases. In particular, with regard to the budget, if tax rates are reduced or if spending is increased, we expect basic employment at the local level to increase. Equation 3 recognizes that, given the national policy variables, an area may achieve faster growth than the average if it possesses supply advantages such as an abundant labor force or natural resources such as favorable topography and water supply. $^{3}$

This model is consistent with many top-down regional models. (For a discussion of such models, see Glickman [6].) Such models also use the economic base approach; they typically explain regional export activity as a function of output in the corresponding industry at the national level. We depart from these models principally in that our underlying model views an area's exports as a direct function of national policy variables rather than of national output variables.

Test of the Model. In converting the general model of equations 1-3 into operational form, we make certain alterations and simplifying assumptions. In particular, we make no effort to identify and measure sources of basic income in the TVA districts. Rather, we concentrate on the role of just one such source, manufacturing, ${ }^{4}$ because it is our view that manufacturing has been the principal source of the region's economic growth in the past and will continue in this role in the future. We first test the hypothesis that the level of real personal income on a per capita basis (PIPC) can be explained by the level of manufacturing activity. That is, we write

$$
\text { PIPC }_{i t}=a_{1}+a_{2} E_{\text {MFG }}+\underset{j}{\sum_{j}} b_{j} S_{j i t}+a_{3} T
$$

where $\mathrm{EMFG}=$ manufacturing employment and $\mathrm{T}=$ time.

The expectation is that $\mathrm{a}_{2}>0$; that is, that relatively high manufacturing employment will result in a high per capita income. We also expect that $\mathrm{a}_{3}$ $>0$, due to rising productivity over time. Finally, if an area enjoys such advantages as water availability, high quality labor force, and favorable topography, we expect it to be able to attract a wider variety of industries, including some with high productivity and wage scales. Such advantages are summarized in $S_{\mathrm{jit}}$, the vector of supply variables.

We test equation 4 using pooled cross section-time series data for the seven TVA administrative districts, with annual observations for PIPC and EMFG, for the period 1968-78. The results are presented in Table 4 for a number of variations of equation 4 . In general, the results are consistent with our hypothesis. In each equation, the coefficient for EMFG is positive and statistically significant.

Of the supply variables included in 4.1-4.5, water availability was established by Garrison and Paulson [5] as a crucial determinant of employment in such industries as pulp and paper, chemicals, primary metals, and rubber and plastics. These tend to be high-wage industries, and Garrison and Paulson found that, in the Tennessee Valley Region, clusters of 
employment in these "water-oriented" industries are located at sites that equal or exceed the threshold level of streamflow (400 cubic feet per second). The positive and statistically significant coefficient found in 4.2 is consistent with the interpretation that clusters of employment in these high-productivity, high-wage industries enhance per capita income.

A similar rationale underlies inclusion of the topography variable, LNDAG, which is measured as percent of land area devoted to agriculture. This variable is intended to demonstrate the constraint faced by hilly and mountainous areas, where suitable industrial sites, especially for large plants, may be unavailable or very costly. Such areas, of course, also are unsuited for agriculture, and it is thus reasoned that, the higher the percent of land area suitable for agriculture, the more favorable the topography for large manufacturing plant sites. If so, employment in industries with economies of large scale (which tend to be capital intensive and high-wage industries) will vary positively with the variable LNDAG, and again per capita income will be enhanced. LNDAG is included in equations $4.2,4.4$, and 4.5 , and the coefficients have the expected sign and are statistically significant.

A third supply variable, median school years completed, was tried as a proxy for quality of the labor force. The coefficient is significant and in the expected direction.

We wish to stress that equations 4.1-4.5 represent an effort to explain the level of per capita income. In our view they support the hypothesis that the level of manufacturing concentrations is an important determinant of differentials in real income per capita. Thus the evidence is consistent with the view that less-urbanized districts (and counties) tend to have lower incomes because of their inheritance of low manufacturing concentrations. It is important to realize that, if an area already has a stock of manufacturing jobs, its real income will grow and remain high due to productivity increases even if employment gains are modest. Finally, the related hypothesis that special advantages such as water availability and favorable topography lead to high productivity and high incomes is supported.

It is also of interest to attempt to explain the rate of growth of per capita income. As noted in Section I, there is a tendency in the TVA Region for districts with low levels of per capita income to have high growth rates of per capita income, and for districts with high income levels to have lower growth rates. Our hypothesis is that less-urbanized areas have for the past two decades enjoyed rapid growth in manufacturing and that this growth has led to rapid gains in per capita income. These areas, however, started the period with low levels of manufacturing and accordingly with low levels of per capita income. Underlying this hypothesis is the view that such areas, while to a considerable extent bypassed prior to 1960 , now possess strong location advantages for manufacturing, leading to a convergence of area incomes. These advantages include a labor supply of adequate quantity (and with desirable characteristics), small-town amenities, and adequate transportation facilities. This view is summarized as: 
(5) PIPCG $_{\text {it }}=c_{1}+c_{2}$ EMFGG $_{i t}+c_{3}$ POPG $_{i t}$,

where

PIPCG = growth rate of personal real income per capita,

EMFGG = growth rate of manufacturing employment, and

POPG $=$ growth rate of population.

The expectation of our hypothesis is that $c_{2}>0, c_{3}<0$. That is, a high rate of growth of EMFG led to a high growth rate of PIPC during the period 1968 to 1978 , given the rate of growth of population. The negative expectation for $\mathrm{C}_{3}$ reflects the process whereby more-urbanized areas with inherited high levels of PIPC continued to grow rapidly in population during the period (due to high employment multipliers, for example), but not as rapidly as less urbanized areas in PIPC. In turn, less urbanized areas grew rapidly in PIPC due in part to starting at lower PIPC levels and in part to rapid growth in manufacturing jobs, accompanied by very modest population gains. Results of the test are reported in Table 5 as equations 5.1 and 5.2. In general, the hypothesis is supported; the coefficients for EMFGG are positive, as expected, and statistically significant. The coefficients for POPG have the expected sign and are significant at the 10 percent level, but not at the 5 percent level. Efforts to discover causal roles

\section{TABLE 5}

Regressions of Growth Rate Of Personal Income

Per Capita On Explanatory Variables, 1968-78, TVA Region ${ }^{a}$

\begin{tabular}{|c|c|c|c|c|c|c|c|}
\hline \multirow[b]{2}{*}{$\begin{array}{l}\text { Equation } \\
\text { Number }\end{array}$} & \multirow[b]{2}{*}{$\begin{array}{c}\text { Dependent } \\
\text { Variable }\end{array}$} & \multicolumn{5}{|c|}{ Independent Variables } & \multirow[b]{2}{*}{$\mathbf{R}^{2}$} \\
\hline & & Constant & EMFGG & POPG & SCHYR & EG & \\
\hline 5.1 & PIPCG & $\begin{array}{c}.021^{* *} \\
(8.27)\end{array}$ & $\begin{array}{c}.423^{* *} \\
(10.25)\end{array}$ & & & & .58 \\
\hline 5.2 & PIPCG & $\begin{array}{l}.023^{* *} \\
(8.40)\end{array}$ & $\begin{array}{c}.443^{* *} \\
(10.53)\end{array}$ & $\begin{array}{r}-.249^{*} \\
(-1.83)\end{array}$ & & & .60 \\
\hline 5.3 & PIPCG & $\begin{array}{c}.027 \\
(0.40)\end{array}$ & $\begin{array}{c}.423^{* *} \\
(10.18)\end{array}$ & & $\begin{array}{c}.058 \\
(-0.09)\end{array}$ & & .58 \\
\hline 6.1 & PIPCG & $\begin{array}{c}.013^{* *} \\
(4.42)\end{array}$ & & & & $\begin{array}{l}.70 * * \\
(10.80)\end{array}$ & .61 \\
\hline 6.2 & PIPCG & $\begin{array}{c}0.15 * * \\
(5.12)\end{array}$ & & $\begin{array}{c}-.337 * * \\
(-2.56)\end{array}$ & & $\begin{array}{c}.75^{* *} \\
(11.44)\end{array}$ & .64 \\
\hline
\end{tabular}

aSee Tables 2 and 3. Regression coefficients marked by * are significant at the 10 percent level. 
played by supply factors (such as educational level: see equation 5.3) proved unsuccessful.

The skeptic of the role of manufacturing might respond that employment growth obviously contributes to income growth, but that manufacturing employment is not unique in this respect. Employment in services, construction, or trade also contributes to income growth. Accordingly, why not write:

(6) PIPCG $_{\text {it }}=d_{1}+d_{2} E_{\text {it }}$,

where $\mathrm{EG}=$ growth rate of total (nonagricultural) employment. We report the results of testing such a relationship in Table 5 as equations 6.1 and 6.2. Obviously PIPCG is closely related to EG. Apparently PIPCG may be explained by either EMFGG or by EG. But this is just another way of saying that EMFGG and EG are closely related. It is our contention that EMFGG is a major determinant of nonmanufacturing growth, and therefore of $\mathrm{EG}$, through the economic base multiplier relationship. (Of course, EMFGG is not the only determinant of EG; there are sources of basic income other than manufacturing.) Thus our view that manufacturing growth is a major source of real income growth in the region remains intact.

The alternative view (that nonmanufacturing employment growth can be the fundamental underlying source of economic growth) must contend that the conformity of EMFGG and EG is coincidental or that growth of nonmanufacturing causes EMFGG. There is no sound economic theory in support of either view (except for the latter in the case of nonexport manufacturing such as food). On the other hand, there exists strong regional economic theory in support of our contention that EMFGG is a determinant of EG:- export earnings from manufacturing support employment in nonbasic industries such as trade and services (equation 2 above).

Implicit in our analysis is the judgment that a rising level of per capita income is an adequate measure of economic well-being. The distribution of income among individuals (or households) within an area is also important, of course. We do not here investigate the relationship between the distribution of income and the per capita level of income. We speculate, however, that a rising income level in an area such as the Mississippi District is accompanied by declining inequality in the distribution of income among households in the district. Stano [8], in a study of income inequality within states, found a significant negative relationship between mean family income and income inequality. Kuznets [7] observed that lower income inequality in advanced countries, as compared to lessdeveloped countries, was due to larger income shares accruing to the middle income classes. We contend that an increase in manufacturing is one force leading to larger shares for these middle groups. This occurs not only because individuals leave the ranks of the unemployed or leave lower-paying jobs, but also because they enter the labor force for the first time (or re-enter after being "discouraged") due to job availability. Thus the labor force participation rate rises; this is manifested in reduced 
outmigration or in an increase in the number of income earners per household. For case-study evidence on this point, see Garrison [3]. Stano's results also are of interest in this relationship; he finds a significant negative relationship between inequality and the percent of the work force employed as craftsmen, clerical workers, and operatives. Manufacturing workers, of course, are preponderantly "operatives."

The final empirical investigation which we conduct is designed to test equation 3 of our general model, which states that an area's basic employment depends on national monetary and fiscal policy as well as local supply variables. Before attempting to test this relationship for TVA administrative districts, however, we refer to some results reported by Garrison and Kort (G-K) [4] in 1980. G-K regress the change in employment (total nonagricultural) at the state level on national monetary and fiscal variables. They test the relationship for the period 1960-1978, using quarterly data. The results are consistent with the view that changes in employment are influenced strongly by national policy actions. It is held by some that Southern states are largely immune to such actions - that growth in the "Sun Belt" has a life of its own and that only the "Frost Belt" is subject to such mundane influences as the business cycle. The pattern that emerges from the G-K study is starkly different: Southern state economies, including those embracing the TVA Region, are becoming increasingly sensitive to national monetary and fiscal actions. The reason lies in the stop-and-go economic policies of the past dozen years as the government periodically fights inflation by introducing restrictive policy and then, when the inevitable recession deepens, reversing itself and stimulating demand through expansionary policy.

We do not here attempt to carry out the G-K type of analysis for the TVA administrative districts, since our employment data are annual rather than quarterly. However, it is possible to approximate the results by making use of a dummy variable technique whereby the employment growth rate in the initial year of the study period, 1968, is treated as a norm. Performance during national recession years then is expected to compare unfavorably with 1968. In general equation form,

$$
\mathrm{EMFGG}_{\mathrm{it}}=\mathrm{F}\left(\mathrm{D} 69, \ldots, \mathrm{D} 78, \underset{\mathrm{j}}{\mathrm{S}_{\mathrm{jit}}}\right),
$$

where D69 = 1 for 1969 and $=0$ otherwise, $\ldots, D 78=1$ for 1978 and $=0$ otherwise, and $S_{j}$ are the same as defined previously.

These results are reported in Table 6 . It must be remembered that the equation attempts to identify the reason(s) for different growth rates as between the administrative districts and as between years. Growth for the entire period was positive, and 1968 was a year of strong positive growth, with a growth rate of 4.6 percent for real GNP. Thus the coefficients for the dummy variables of recession years should be negative. This expectation is borne out in the results, and we conclude that this test using pooled data for the administrative districts is consistent with the G-K findings for states. In Table 6 we show also the results of experimenting with supply 
TABLE 6

Regression of Growth Rate of Manufacturing Employment On Independent Variables, 1968-78, TVA Region ${ }^{\mathrm{a}}$

\begin{tabular}{|c|c|c|c|c|c|}
\hline \multirow{3}{*}{$\begin{array}{c}\begin{array}{c}\text { Independent } \\
\text { Variable }\end{array} \\
\text { Constant }\end{array}$} & \multicolumn{5}{|c|}{ Equation Number } \\
\hline & \multicolumn{2}{|c|}{7.1} & \multicolumn{2}{|c|}{7.2} & 7.3 \\
\hline & .052 & $(6.81)^{* *}$ & .036 & $(2.66)^{* *}$ & $.021 \quad(0.31)$ \\
\hline D69 & -.004 & $(-0.40)$ & -.004 & $(-0.41)$ & $-.004(-0.40)$ \\
\hline D70 & -.059 & $(-5.48) * *$ & -.059 & $(-5.71)^{* *}$ & $-.059(-5.50)^{* *}$ \\
\hline D71 & -.045 & $(-4.19)^{* *}$ & -.045 & $(-4.37)^{* *}$ & $-.045(-4.21)^{* *}$ \\
\hline D72 & .018 & $(1.63)$ & .018 & $(1.70)^{*}$ & $.018 \quad(1.64)$ \\
\hline D73 & .009 & $(0.80)$ & .009 & $(0.84)$ & $.009 \quad(0.81)$ \\
\hline D74 & -.059 & $(-5.48)^{* *}$ & -.059 & $(-5.72)^{* *}$ & $-.059(-5.51)^{* *}$ \\
\hline D75 & -.171 & $(-15.77)^{* *}$ & -.171 & $(-16.46)^{* *}$ & $-.171(-15.85)^{* *}$ \\
\hline D76 & .020 & $(1.83)^{*}$ & .020 & $(1.91)^{*}$ & $.020 \quad(1.84)^{*}$ \\
\hline D77 & -.004 & $(-0.36)$ & -.004 & $(-0.38)$ & $-.004(-0.36)$ \\
\hline D78 & -.016 & $(-1.48)$ & -.016 & $(-1.54)$ & $-.016(-1.49)$ \\
\hline LNDAG & & & .519 & $(2.66)^{* *}$ & $.270 \quad(1.62)$ \\
\hline PERBL & & & -.579 & $(-2.26)^{* *}$ & \\
\hline SCHYR & & & & & $(0.26)$ \\
\hline $\mathrm{R}^{2}$ & .89 & & .90 & & .89 \\
\hline
\end{tabular}

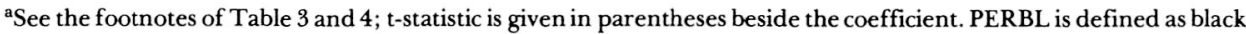
population as a percent of a district's total population.

variables. In equation 7.2, it is seen that LNDAG has the expected sign. In addition, the independent variable PERBL, black population as a percent of a district's total population, has a negative influence. We interpret this as evidence that rural and small-town areas with large black populations face a disadvantage in attracting new manufacturing industry.

\section{SUMMARY}

The principal conclusions of this study of seven smaller areas within the Tennessee Valley Region are:

1. The level of manufacturing employment is a major determinant of differentials in the level of real per capita income.

2. The rate of growth of manufacturing employment is a major determinant of the rate of growth of real per capita income. As a related finding, the evidence suggests that less-urbanized areas of the region enjoy especially rapid rates of growth in manufacturing. Further, these areas tend to have relatively low levels of per capita income, and their manufacturing growth permits a highly desirable improvement in living standards and a reduction of income differentials within the region. 
3. The rate of growth of manufacturing employment has become increasingly sensitive to national monetary and fiscal policy actions. This is true not only at the national level but also at the state and local-area levels in the Tennessee Valley region.

The latter development is somewhat ironic in that most analysts explain economic growth in the South by focusing on the South's advantages compared to the older industrial areas of the Northwest and Midwest. Indeed this view was correct in the $1960 \mathrm{~s}$, when growth at the national level was quite steady. During this period manufacturing growth in the Tennessee Valley region also was steady and at a rate well in excess of the national rate. Further, less-urbanized areas in the region grew even more rapidly. For the past 10 or 12 years, however, national economic policy has been of the stop-and-go variety, alternately producing periods of recession (1970-71, 1974-75, and 1979-80) and periods of expansion (1972-73 and 1975-78).

Our conclusion is that, for the less-urbanized, lower-income areas of the region, manufacturing has been the principal source of real income improvement for the past two decades. Further, manufacturing promises to be the major route to continued improvement in the future. Manufacturing is also important as a source of growth in more urbanized areas. However, such areas have inherited high levels of income and also tend to have other sources of basic income as well as relatively high income and employment multiplier effects. These sources of income growth are much less available to less-urbanized areas, however. The latter areas now find themselves increasingly at the mercy of national policy actions and the national business cycle.

\section{FOOTNOTES}

\begin{abstract}
${ }^{1}$ An alternative way of measuring urbanization would be to calculate the fraction of a district's population accounted for by "urban places." But such places require a population of only 2,500 to qualify as "urban." As will become evident below, we consider the major way in which districts differ demographically is in the presence or absence of a metropolitan area, because such areas provide a much greater variety of goods and services than do small communities.

${ }^{2}$ Actually, the relevant budget measure is that yielded by the "high-employment budget." The actual federal
\end{abstract}

budget is not a useful indicator of the direction of fiscal policy.

${ }^{3}$ Equations 1-3 constitute a recursive system, and therefore no simultaneous-equation estimating method is needed. Ordinary least squares can provide unbiased and consistent estimates of the parameters and their standard errors.

${ }^{4}$ It is a simplification, of course, to consider all manufacturing as basic. Some manufacturing (e.g., food) is not export-oriented but rather serves the local population.

\section{REFERENCES}

1. Browne, Lynn, "Narrowing Regional Income Differentials," New England Economic Review (Sept./Oct. 1980): 35-56.

2. Garrison, Charles B., "Industrial Growth in the Tennessee Valley Region," American Journal of Agricultural Economics 56 (Feb. 1974): 50-60.

3. - "The Impact of New Industry: An Application of the Economic Base Multiplier to Small Rural Areas," Land Economics XLVIII (Nov. 1972): 329337.

4. _ and John R. Kort, "The Increasing Sensitivity of State Employment Levels to National Economic Policy Actions," paper presented at Southern
Economic Association, Washington, D.C., Nov. 1980. 5. and Albert S. Paulson, "Effect of Water Availability on Manufacturing Employment in the Tennessee Valley Region," Water Resources Research 8 (April 1972): 301-316

6. Glickman, Norman J., Econometric Analysis of Regional Systems. New York: Academic Press, 1977.

7. Kuznets, Simon, "Economic Growth and Income Inequality," American Economic Review XLV (March 1955): $1-28$

8. Stano, Miron, "State Variations in Income Inequality: A Multiple-Equation Approach," The American Economist 25 (Spring 1981): 10-19. 